\title{
Uma análise sistêmica: vitimização e políticas de segurança em São Paulo
}

Betânia Peixoto; Letícia Godinho de Souza e Renato Sérgio de Lima

\section{Introdução}

Criadas nos EUA, entre as décadas de 1940 e 1960, as pesquisas de vitimização buscam investigar a subnotificação criminal, ou seja, o percentual de casos que, por diferentes razões, não chegam ao conhecimento oficial das polícias e do estado. Elas são um complemento às estatísticas criminais baseadas nos registros policiais e ganharam força a partir da aceitação do fato de que crimes e criminosos, longe de serem fatos em si, são construções sociais. Assim, estão sujeitos a uma série de processos sociais, políticos e culturais que precisam ser mais bem mensurados e analisados, quando da investigação acerca dos seus determinantes e do desenho de políticas públicas. As pesquisas de vitimização são hoje um poderoso instrumento de trabalho no planejamento de políticas de segurança pública que pretendam considerar simultaneamente o movimento da criminalidade e a sua percepção pela população, e que pretendam lidar com o crime, o medo e a insegurança gerada na população. 
Em termos teóricos, elas são tributárias dos estudos sobre grupos sociais desviantes, com destaque para Goffman (1996), Becker (1985) e os pesquisadores da nova escola sociológica de Chicago. Tais autores solidificaram a interpretação de que uma determinada conduta se converte num crime se for assim percebida pela opinião coletiva, ao passo que conduta semelhante não é lida do mesmo modo se a opinião coletiva não a percebe como desviante. Ademais, desde a década de 1940, consolidou-se o entendimento de que as estatísticas oficiais de criminalidade registram apenas uma parcela dos crimes que são cometidos. Nesse sentido, o estudo da subnotificação criminal fornece a base empírica para a interrogação sobre os critérios de seleção e funcionamento dos mecanismos oficiais de resolução de conflitos, bem como sobre as diferenças entre a percepção e a incidência de crimes e da violência.

É nessa direção que, como bem lembra um antigo estudo da Fundação João Pinheiro sobre indicadores sociais de criminalidade, a disponibilidade de estatísticas vai variar conforme o grau de transparência social do fenômeno por elas descrito, ou seja, variáveis públicas e definidas por meio de normas legais claras são mais fáceis de serem medidas do que percepções ou, mesmo, atos ilegais (FUnDAÇÃO Jỗo PINHEIRO, 1987).

Soma-se ao problema da subnotificação, que incide em diversos países, o fato de os registros oficiais de criminalidade, no Brasil, serem produzidos ainda em um contexto de estruturas organizacionais e marcos legais herdados do período autoritário, no qual a disponibilidade, a confiabilidade e a publicidade de informações são muitas vezes questionáveis. Nesse contexto, as pesquisas de vitimização são ferramentas essenciais, porém recentes, na política de segurança pública no Brasil - a primeira foi realizada pelo IBGE em 1988 e, de lá para cá, os estudos existentes ainda são esporádicos e assistemáticos.

No Município de São Paulo, destacamse as pesquisas conduzidas pelo Insper nos anos 2003 e 2008. É com base nessas pesquisas que o presente artigo baseia suas análises sobre cinco tipos de vitimização tradicionalmente considerados pelos estudiosos e gestores da área da segurança urbana: roubo a pessoa, furto a pessoa, roubo e furto a residência, roubo e furto de veículo e agressão física.

Neste trabalho, analisamos os determinantes da vitimização em São Paulo, ao longo do tempo, por meio de perspectiva sistêmica da dinâmica criminal (KasArda e JanOWITZ, 1974; BursiK, 1993; Sampson e Groves, 1989). Dentro dessa perspectiva, é possível compreender os motivos das mudanças no padrão de vitimização entre 2003 e 2008 e explicar as diferenças nesse padrão de mudanças de acordo com o tipo de crime. Segundo relatório do Insper (2009), as estatísticas descritivas das características dos entrevistados são similares entre os anos, permitindo a comparação dos resultados.

Partimos do pressuposto de que o fenômeno da vitimização deve ser analisado de forma mais ampla do que apenas focar sobre as características individuais, necessitando incorporar na análise características do(s) local (is) em que os indivíduos estão inseridos. Dessa forma, utilizamos uma combinação de banco de dados: os bancos de dados de vitimização no Município de São Paulo (Pesquisa Insper para os anos de 2003 e 2008) e dois bancos de dados complementares: um que contém características dos distritos administrativos de São Paulo (Fundação Seade), e outro com indicadores das regiões homogêneas do 
município (Pesquisa Mensal de Emprego e Desemprego - Seade e Dieese).

A probabilidade de vitimização foi relacionada a fatores referentes a três níveis de análise: no primeiro nível, a variável dependente seria uma função dos atributos relacionados aos próprios respondentes; no segundo, dos fatores relacionados ao distrito administrativo onde o respondente reside (a cidade de São Paulo está dividida em 97 distritos administrativos); e no terceiro nível, das características da região homogênea da qual o indivíduo faz parte (são nove, ao todo, no município). A suposição que subjaz ao modelo é a de que as características individuais e os insumos sociais, locais e macrolocais de onde o indivíduo circula seriam importantes determinantes da probabilidade de vitimização.

Entender a criminalidade por meio da perspectiva do local onde ocorre, incorporada à ideia de uma análise sistemática da dinâmica criminal, fornece, a nosso ver, maior amplitude à compreensão do processo pelo qual a criminalidade se instaura e se mantém em determinadas áreas da cidade. Nessa perspectiva, a criminalidade é explicada por meio da interação entre as características individuais, os padrões de interação social e espacial, sua organização e a influência das instituições públicas e privadas nessas racionalidades.

\section{Vitimização e políticas de segurança pública em São Paulo}

De maneira geral, a pesquisa mostra uma redução nas taxas de vitimização, que variou de $-0,4 \%$ a $-1,9 \%$ entre os anos para os crimes de furto a pessoa, roubo e furto a residência, roubo e furto de veículo e agressão física. Apenas a vitimização por roubo a pessoa aumentou em 1\%, comparando-se de 2008 a 2003 (ver Tabela 1). O presente estudo busca entender essa variação, focando-se sobre os diferenciais apresentados por essas dinâmicas de vitimização.

Tanto a literatura acadêmica quanto as estatísticas oficiais ressaltam uma importante inversão no quadro da insegurança pública em São Paulo nos anos 2000. Diferentemente das duas décadas anteriores, quando o fenômeno da criminalidade foi caracterizado por um constante

Tabela 1: Estatísticas descritivas da vitimização

\begin{tabular}{l|c|c|c|c|l}
\hline \multirow{2}{*}{ Vitimização } & \multicolumn{2}{|c|}{2003} & \multicolumn{2}{c|}{2008} & \multirow{2}{*}{ Diferença } \\
\cline { 2 - 5 } & média & sd & média & sd & média (2) \\
\hline Roubo a casa & 0,063 & 0,242 & 0,058 & 0,234 & $-0,00427$ \\
Roubo a pessoa & 0,025 & 0,157 & 0,035 & 0,184 & $0.010^{* * * *}$ \\
Furto a pessoa & 0,054 & 0,226 & 0,049 & 0,216 & -0.005 \\
Roubo de veículo(1) & 0,079 & 0,270 & 0,060 & 0,237 & $-0.019^{* *}$ \\
Agressão física & 0,040 & 0,196 & 0,027 & 0,161 & $-0.013^{* * *}$ \\
\hline
\end{tabular}

Fonte: Elaboração própria - Pesquisas de vitimização 2003/2008 do Insper.

Nota:

1) As estatísticas para roubo de veículo foram calculadas considerando apenas os indivíduos que tinham veículo.

2) Os asteriscos se referem à significância do teste de diferença de médias: * significativo a 10\%; ** significativo a $5 \% ; * * *$ significativo a $1 \%$. 
aumento, nos anos 2000 o Município de São Paulo apresentou uma forte redução de boa parte dos crimes, especialmente os homicídios. Entre 2003 e 2008, essa variação foi de mais de 70\%, com 1622 mortes por agressão em 2008 contra 5591 mortes em 2003.

Embora exista acordo entre estudiosos e gestores da área quanto aos fatores que deram causa a essa nova tendência, é consenso que houve mudança de atuação por parte dos órgãos responsáveis pela segurança pública. Estudo da Fundação Seade, elaborado para a Secretaria de Justiça e Defesa da Cidadania de São Paulo, ressalta uma série de fatores relacionados aos processos sociais, políticos e institucionais que devem ser considerados acerca da atuação do estado no campo da segurança pública e da prevenção da violência (LIMA, 2011).

Apesar das mudanças na atuação do Estado de São Paulo, este ainda carece de sistemas de informações padronizados e que permitam análise mais detalhada dos determinantes da criminalidade e da vitimização. $\mathrm{O}$ que é possível observar é o avanço na redução dos homicídios, confirmado por várias fontes, constituindo um sucesso inegável das políticas de segurança implementadas no estado e no município. Contudo, esse movimento não parece ser acompanhado pelos demais delitos; há, ao que tudo indica, um descolamento entre os determinantes da vitimização por homicídios em relação aos observados, sobretudo, para os crimes patrimoniais (roubo e furto).

\section{Seleção das variáveis e hipóteses consideradas}

\section{Crimes}

As variáveis a serem explicadas pelos modelos são as vitimizações por crimes, que foram analisadas separadamente: vitimização por crime de roubo/furto a residência, por roubo/furto de veículo, roubo contra a pessoa, furto contra a pessoa e agressão física. A análise separada dessas categorias deveu-se ao suposto de que cada um desses fenômenos possui uma dinâmica criminal específica.

\section{Nível 1: indivíduos}

Para determinar os perfis de risco individuais, empregamos os dados provenientes da pesquisa de vitimização do Insper, dos quais selecionamos, em primeiro lugar, atributos individuais: idade, cor/raça, sexo, escolaridade, dummy para natural do Estado de São Paulo, dummy para economicamente ativo e classe social ${ }^{1}$. As variáveis escolaridade e classe social apresentaram número muito alto de missings (32\% e 38\% respectivamente), tendo sido, portanto, retiradas do modelo. Incluímos dummy para número de banheiros (2 ou + ), número de residentes no domicílio (indicadores comumente utilizados na literatura como proxies de situação socioeconômica) e local de residência (casa ou apartamento).

Incorporamos, outrossim, indicadores de situações consideradas "protetivas", como tempo de moradia no local e se o imóvel onde o respondente reside é próprio. A literatura anglo-saxônica, que utiliza com mais frequência essas variáveis, supõe que quanto maior o tempo de residência no local, ou sendo o morador proprietário do imóvel, maior sua predisposição para tomar iniciativas no sentido de proteger, tanto o imóvel quanto a vizinhança onde reside, da atividade criminal predatória. Essas iniciativas podem incluir desde a contratação de serviços ou compra de equipamentos de segurança, até a mobilização coletiva (Skogan, 1990).

Construímos um índice de participação comunitária, de interação com os vizinhos, 
de atividades comunitárias e um indicador de confiança interpessoal. Por um lado, as teorizações (principalmente por parte da literatura norte-americana e inglesa) acerca da mobilização comunitária e da participação em estratégias de segurança pública - tais como policiamento comunitário, fóruns comunitários para discussão dos problemas de insegurança, criação de redes de vizinhos para vigilância e proteção mútua - apostam no seu papel também protetivo, não somente em face da criminalidade, mas também da vitimização por crimes (SAMPSON e GROVES, 1989; SAMPSON et al., 1997; CRAWFORD, 2004).

Por outro lado, no contexto brasileiro, as localidades com maior incidência de participação e mobilização comunitária constituem, em geral, comunidades de baixa renda, que concentram maior número de criminosos - tais como conhecidos pelo sistema de justiça criminal - e maior número de vítimas de crimes (ZaLUAR, 1997; Adorno, 2002). Portanto, esperamos que os resultados encontrados por essas variáveis sejam contrários aos presentes na literatura internacional, pois em países desenvolvidos as participações e mobilizações comunitárias são típicas de comunidades de classe média.

Por fim, incorporamos indicadores de atividades rotineiras e/ou estilo de vida, seguindo a teorização de Cohen e Felson (1979) e Hindeland et al. (1978).

O modelo teórico sobre o estilo de vida, Life-style model, considera que a diferença no estilo de vida dos indivíduos afeta as situações em termos de menor ou maior risco de vitimização. $O$ estilo de vida adotado pelos indivíduos dependeria da forma como se adaptam ao papel que a sociedade espera que desempenhem e às restrições estruturais, as quais são determinadas, fundamentalmente, pelo nível de renda e pela estrutura ocupacional.
Numa perspectiva similar, a teoria das atividades rotineiras, Routine activity approach, desenvolvida por Cohen e Felson (1979) também é comumente utilizada para explicar a relação entre certos atributos individuais e as chances de ser vitimado por crimes. Os autores consideram que fundamental para determiná-las é a dinâmica que propicia a convergência entre ofensor e vítima no tempo e no espaço. Assim, o fator proximidade (entre vítima e

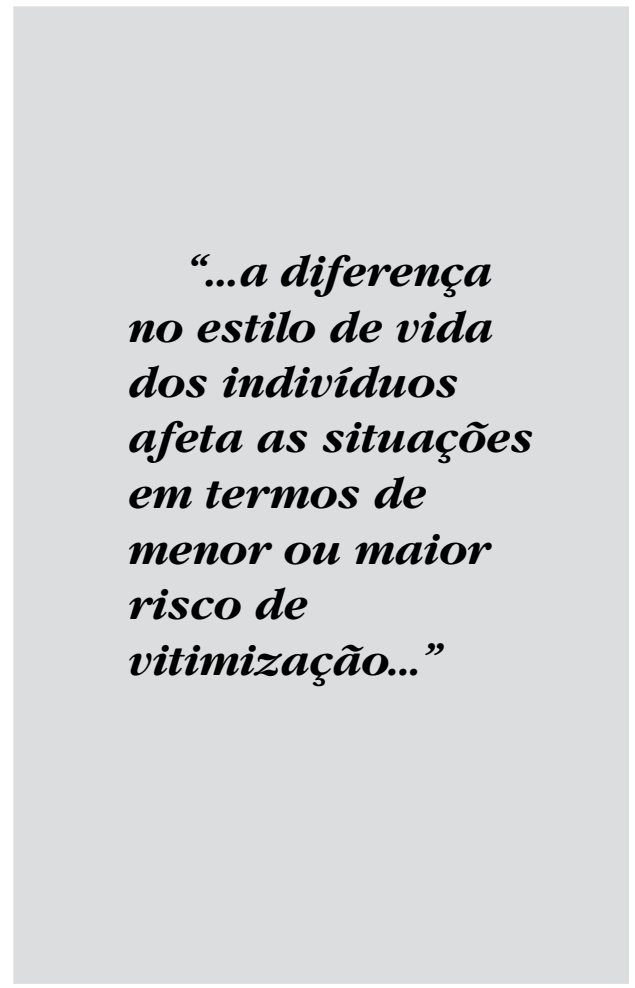

ofensor) estaria intrinsecamente relacionado à chance de ocorrer o evento de vitimização. Os padrões de uso do tempo por parte dos indivíduos, entre atividades de trabalho e lazer, jogariam papel fundamental na determinação da proximidade entre vítima e ofensor.

Cohen et al. (1981) incluem duas outras dimensões que afetariam de maneira 
importante os riscos de vitimização: exposição e atratividade da vítima em potencial. "Exposição" referir-se-ia à visibilidade e acessibilidade física da pessoa ou do objeto para o criminoso. "Atratividade" representaria o desejo simbólico ou material que o indivíduo ou a propriedade-alvo supostamente desperta no ofensor motivado. Assim, padrões de uso do tempo, exposição e atratividade facilitariam a oportunidade ou o risco de ocorrência do evento de vitimização ${ }^{2}$.

Com base nessa abordagem, incluímos supostos fatores do ambiente ou da rotina de vida dos indivíduos, que aumentariam as "oportunidades" de vitimização: utilização de meio de transporte (particular ou público); frequência a bares; índice de frequência em atividades de lazer externas ou religiosas; posse de arma e uso regular de bebida alcoólica. Essa perspectiva parece ter sido a mais comum nos estudos que analisaram dados de vitimização para o contexto brasileiro (BEATO et al., 2004).

A natureza longitudinal dos dados permitiu a incorporação, nos modelos, de variáveis relacionadas à trajetória passada e contemporânea do indivíduo (variável $t$ ).

\section{Níveis 2 e 3: distritos administrativos e regiões homogêneas}

O modelo procurou explicar a vitimização sob a ótica sistêmica de forma a não incorrer na falácia ecológica (não inferir relações em nível individual baseadas em dados agregados) e na falácia individualista (não supor que as relações causais necessariamente geram correlações no nível do indivíduo, pois podem ser confundidas com processos de nível comunitário).

A inclusão da mediação dos diferentes níveis, para além do nível individual - comunitário, macrossocial e político -, na determinação do risco de vitimização é importante. É razoável supor que indivíduos com mesmo perfil apresentem variação na probabilidade de vitimização, dependendo do local onde residam. Dito de outro modo, as condições socioeconômicas e outros fatores que caracterizam as distintas localidades no interior do espaço da cidade provocam diferentes riscos ou oportunidades de vitimização.

Ademais, os distintos perfis dessas localidades e, consequentemente, o risco de vitimização a que está submetida a população residente mudam conforme os padrões de políticas públicas ou de atuação dos governos. Muitas das características das localidades, que indicariam ineficácia coletiva ou desorganização social (tais como instabilidade residencial, concentração de famílias pobres, com crianças e monoparentais chefiadas por mulheres, conjuntos habitacionais, entre outros), parecem ser afetadas diretamente pelas ações governamentais e fatores externos. Assim, fatores políticos e transformações estruturais mais amplas também deveriam ser considerados no modelo (SKOGAN, 1990; Wilson, 1987; SAmpson e Wilson, 1995; Hope, 2001).

$\mathrm{Na}$ literatura anglo-saxônica, a perspectiva sistêmica é analisada a partir do conceito de organização social (KASARDA e Janowitz, 1974; Bursik, 1988; SAMPSON e Groves, 1989). A desorganização social é, portanto, uma característica das diferentes comunidades que são impactadas por diversos processos, como pobreza, rotatividade populacional, padrão de atuação dos governos, políticas públicas, entre outros fatores.

Sampson e Wilson (1995) consideram três perspectivas na análise da dimensão estrutural ou do grau de organização social 
das comunidades: concentração de pobreza, desestruturação familiar e instabilidade residencial ${ }^{3}$. Land et al. (1990) captaram a relevância da privação relativa, da dissolução familiar e da urbanização ${ }^{4}$ na determinação de padrões de vitimização. Outros autores incorporam variáveis que mensuram o grau de eficácia coletiva das comunidades: Sampson et al. (1997) estimaram empiricamente a operação desse mecanismo no nível comunitário e seu papel mediador dos processos advindos do nível macro, e a incidência de crime violento e desordem emergente no nível micro ${ }^{5}$. Sampson e Groves (1989) analisaram a prevalência e interdependência das redes sociais na determinação da capacidade de supervisão coletiva de uma comunidade, para dar conta dos problemas de criminalidade locais ${ }^{6}$.

Assim, procuramos incorporar fatores que possivelmente ajudam a explicar a existência de diferentes padrões entre as localidades, no espaço intraurbano, e que, ao impactarem o seu grau de organização, determinam sua maior ou menor capacidade de fazer diante dos fenômenos do crime e da vitimização. Buscamos informações que servissem como indicadores da atuação governamental e das mudanças econômicas e sociais, majoritariamente promovidas por ela.

Tais informações são quase inexistentes no nível intraurbano, gerando dificuldades de encontrar indicadores disponíveis. No caso de indicadores de segurança pública, faltam registros ou estes são extremamente frágeis; ademais, muitos não são georreferenciados ou são suficientemente desagregados para se proceder a uma análise tal como a proposta; há ainda a incompatibilidade entre as divisões territoriais utilizadas pelo município (distritos administrativos e regiões homogêneas) e os órgãos de segurança pública (distritos policiais). Para o caso dos demais indicadores, poucas pesquisas costumam coletar dados em nível mais desagregado do que o municipal. Ademais, não poderíamos usar dados dos censos demográficos, caso quiséssemos entender a variação entre os anos 2003 e 2008 - havia dados disponíveis somente para o ano 2000.

Logo, para o nível dos distritos administrativos, consideramos as seguintes variáveis: percentual de nascidos vivos com baixo peso (menos de $2.500 \mathrm{~g}$ ); percentual de nascidos vivos de mães adolescentes; densidade populacional. Utilizamos, para o nível das regiões homogêneas, as seguintes variáveis: percentual de famílias com até meio salário mínimo; percentual de jovens de 15 a 17 matriculados no ensino médio; percentual da população ocupada com carteira assinada.

\section{Indicador de política de segurança pública}

Incorporamos ao modelo um indicador da política de segurança pública. Devido a variados fatores, como ausência ou fragilidade de demais dados, a política de segurança tem sido amplamente pautada pelos indicadores de homicídio. Assim, esses são atualmente considerados tanto indicadores de planejamento quanto de avaliação dos resultados da política de segurança praticada pelos diferentes níveis de governo. Os dados incluídos neste estudo encontramse desagregados por distritos administrativos, o que ajuda, de alguma maneira, a testar o foco e a efetividade das ações de prevenção à criminalidade e à vitimização. O Quadro 1 mostra as variáveis incorporadas no modelo e o Anexo I apresenta as tabelas descritivas dessas variáveis. 


\section{Quadro 1: Variáveis consideradas por grupo analítico}

\begin{tabular}{|c|c|}
\hline Grupos analíticos & Nome das variáveis \\
\hline Atributos individuais & $\begin{array}{l}\text { Local de residência-casa } \\
\text { Número de residentes no domić́lio } \\
\text { Dois ou mais banheiros } \\
\text { Escolaridade } \\
\text { primário comp./fund. incompleto } \\
\text { fund. comp./médio incompleto } \\
\text { médio comp./sup. incompleto } \\
\text { ensino superior ou mais } \\
\text { Classe social } \\
\text { classe C } \\
\text { classe B } \\
\text { classe A } \\
\text { Idade } \\
\quad \text { jovens adultos - } 25 \text { a } 34 \text { anos } \\
\text { adultos - } 35 \text { a } 59 \text { anos } \\
\text { Idoso - maior } 60 \\
\text { Cor - branco } \\
\text { Sexo - homem } \\
\text { Estado de origem - São Paulo } \\
\text { PEA }\end{array}$ \\
\hline Fatores protetivos & $\begin{array}{l}\text { Situação da residência - própria } \\
\text { Tempo de moradia }\end{array}$ \\
\hline Atividades rotineiras & $\begin{array}{l}\text { Meio de transporte no dia a dia } \\
\text { carro/moto - particular } \\
\text { público } \\
\text { Frequência a bares } \\
\text { raramente } \\
\text { frequentemente } \\
\text { Índice-freq. lazer externos } \\
\text { Posse de arma } \\
\text { Uso de bebida alcoólica } \\
\text { socialmente } \\
\text { frequentemente }\end{array}$ \\
\hline Envolvimento comunitário & $\begin{array}{l}\text { Índice - participação comunitária } \\
\text { Interação com o vizinho } \\
\text { Índice - atividades comunitárias }\end{array}$ \\
\hline Confiança interpessoal & Índice - confiança interpessoal \\
\hline Política de seg. pública & Taxa de homicídio (por cem mil) \\
\hline Política pública - distrito & $\begin{array}{l}\text { Taxa de mortalidade infantil (por mil) } \\
\% \text { Nascidos vivos com baixo peso } \\
\text { Densidade demográfica }(\mathrm{Km} 2)\end{array}$ \\
\hline Política pública - região homogênea & $\begin{array}{l}\% \text { famílias com até } 1 / 2 \text { salário mínimo } \\
\% \text { jovens de } 15 \text { a } 17 \text { anos não freq. escola } \\
\% \text { de populaçao ocupada carteira assinada }\end{array}$ \\
\hline
\end{tabular}


Estratégia de estimação e discussão dos resultados

\section{A não hierarquia nos dados}

A princípio, o instrumental analítico mais adequado para a construção de um modelo sistêmico da dinâmica da vitimização seria o modelo hierárquico longitudinal.

Formalmente, na estimação dos modelos hierárquicos consideramos no nível 1 os indivíduos, no nível 2 os distritos administrativos e no nível 3 as regiões homogêneas. As informações em todos os níveis estão disponíveis para dois momentos no tempo (anos de 2003 e 2008). Especificamos um modelo hierárquico logit longitudinal para vitimização com indivíduos i associados a distritos administrativos J que, por sua vez, são associados a regiões homogêneas K:

Logit $\left\{\operatorname{Pr}\left(Y_{\mathrm{ijk}}=1 \mid \mathrm{x}_{\mathrm{ijk}}, \varsigma_{\mathrm{jk} k}^{2}, \varsigma_{\mathrm{k}}^{3}\right\}=\beta_{1}+\sum \beta \mathrm{x}_{\mathrm{ijk}}+\varsigma_{\mathrm{jk}}^{2}+\varsigma^{3} \mathrm{k}\right.$

Onde: $x_{\mathrm{ijk}}$ é o vetor contendo as covariadas em todos os níveis e $\grave{o}_{j \mathrm{k}}{ }_{\mathrm{j}} \mid \mathrm{x}_{\mathrm{ijk}}, \grave{\mathrm{O}}_{\mathrm{k}}^{3}$ é um intercepto randômico sobre os distritos (nível 2) e $\grave{o}^{3}{ }_{\mathrm{jk}} \mid \mathrm{x}_{\mathrm{ijk}}$ randômico variando sobre as regiões homogêneas (nível 3). Como usual, os efeitos randômicos são assumidos independentes um do outro e entre clusters (RABEHeskethe e Skrondal, 2008).

Entretanto, nem sempre os modelos hierárquicos se adequam perfeitamente à estrutura de variabilidade dos dados, como ocorrido na primeira estimação realizada neste trabalho. Os resultados da estimação dos modelos hierárquicos logísticos longitudinais mostraram que $\grave{o}_{j \mathrm{k}}^{2}$ e $\grave{o}_{\mathrm{k}}^{3}$ não foram estatisticamente significativos.

Uma primeira explicação para esse resultado reside na consideração de que os atributos do nível individual são suficientes ou mais relevantes para explicar a chance de vitimização no Município de São Paulo do que os atributos das comunidades, captados por meio dos distritos administrativos e regiões homogêneas. Nesse contexto, residir em uma unidade territorial específica não faz diferença para a chance de vitimização. Entretanto, essa explicação nos parece simplista e acreditamos que a não hierarquia dos dados pode residir no fato de que as regiões homogêneas são unidades territoriais/

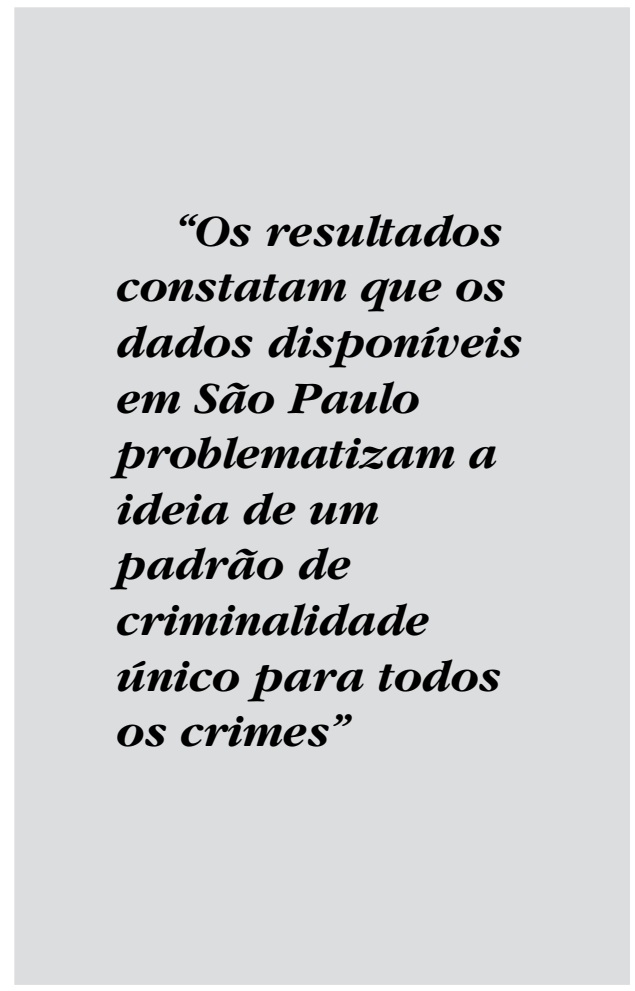

administrativas que foram criadas há muitas décadas, não tendo mantido ao longo do tempo sua homogeneidade sociourbana. Sua constituição é proveniente de um estudo da Secretaria de Economia e Planejamento do Estado de São Paulo (Seplan) em 1977. Baseado nos dados do Censo de 1970, cada distrito da cidade foi analisado a partir de um amplo 
conjunto de variáveis socioeconômicas e demográficas, verificando-se que se encontravam distribuídos em oito regiões homogêneas. Apesar do Município de São Paulo ter mantido, em parte, o padrão centro-periferia que lhe foi característico em boa parte do século XX, a cidade dos anos 2000 é mais diversa e fragmentada; seu padrão atual de distribuição dos grupos sociais, das atividades econômicas e das relações intraurbanas no território é muito mais heterogêneo.

O mesmo argumento vale para os distritos administrativos, unidades que foram criadas antes mesmo das regiões homogêneas. Aqui, vale um paralelo com os registros administrativos de ocorrências policiais. Conforme dados publicados pela Secretaria de Segurança, há forte predomínio de registros de furtos e roubos nos distritos policiais localizados na região conhecida como centro ampliado da capital e, em sentido inverso, grande concentração dos registros de homicídios em distritos policiais localizados na periferia, com ênfase na região sul da cidade. Esse padrão tem se mantido ao longo da década de 2000, não obstante a redução dos homicídios, e indica que a prevalência das ocorrências possui forte correlação espacial (Lima e Tomesani, 2010).

\section{Resultados dos modelos logit}

Tendo em vista a não adequação da estrutura dos dados aos modelos hierárquicos logísticos longitudinais, a estratégia de estimação adotada, em seguida, foi estimar os modelos logísticos considerando o tempo como uma variável de controle, e as variáveis dos níveis distrital e regional afetando diretamente a probabilidade de vitimização ${ }^{7}$. Estimamos a seguinte equação logit incluindo uma dummy de tempo (denominada tempo):
$\operatorname{Logit}\left\{\operatorname{Pr}\left(\mathrm{Y}_{\mathrm{ijk}}=1 \mid \mathrm{x}_{\mathrm{ijk}}\right\}=\right.$ tempo $+\sum \beta \mathrm{x}_{\mathrm{ijk}}+\xi$

Onde $\xi$ equivale ao erro do modelo.

A Tabela 2 apresenta os resultados dos modelos logit estimados para cada dinâmica de vitimização. Os modelos se mostraram estáveis quando estimados em blocos de variáveis para cada grupo considerado, cujos resultados encontram-se no Anexo II $^{8}$. Apesar da redução em 2008 para todas as dinâmicas de vitimização - com exceção da vitimização por roubo a pessoa -, alguns resultados trazem importantes indicações.

Para o caso da vitimização por furto ou roubo a residência, os fatores que a afetaram significativamente foram: morar em casa, ter carro particular, morar em residência com dois ou mais banheiros, número de residentes no domicílio, sexo, idade (adultos tem menores chances com relação a jovens), frequência em atividades de lazer externas, fazer uso de bebidas alcoólicas, posse de arma, interação com vizinhos, participar de atividades comunitárias, maior confiança interpessoal. Cabe lembrar que essas variáveis devem ser analisadas com cautela quando a vitimização considerada é de roubo/furto a residência, pois são atributos apenas do respondente. Ao analisá-las, estamos inferindo que os atributos do respondente são similares para todos os residentes.

Aumenta a probabilidade de ser vítima de roubo o fato de a pessoa: ser mulher, ser de faixa etária diferente da "jovem" (todas as faixas têm menores chances se comparadas à dos jovens), frequentar atividades de lazer externas, frequentar bares e morar em um distrito com redução nas taxas de homicídio (a variável afeta o fenômeno negativamente, ou seja, a probabilidade de vitimização por roubo aumenta à medida que diminuem os homicídios no distrito administrativo). 
Tabela 2: Resultados da estimação dos modelos

\begin{tabular}{|c|c|c|c|c|c|c|}
\hline \multirow{2}{*}{ Grupos analíticos } & \multirow{2}{*}{ Variáveis } & \multicolumn{5}{|c|}{ Odds ratio estimada (1) } \\
\hline & & re & rp & fp & af & rv \\
\hline \multirow{13}{*}{ Atributos individuais } & Tempo & 1,17 & 1,06 & 0,66 & $0.42^{* *}$ & 0,44 \\
\hline & Local de residência-casa & $1.57^{* * * *}$ & 0,86 & 0,84 & 1,34 & 1,00 \\
\hline & Número de residentes no domicílio & $1.06^{* *}$ & 1,03 & 0,97 & $1.10^{* * * *}$ & 1,08 \\
\hline & Dois ou mais banheiros & $1.25^{* *}$ & 1,07 & 0,97 & $0.74^{* \bullet}$ & 1,06 \\
\hline & Idade & & & & & \\
\hline & jovens adultos - 25 a 34 anos & 0,89 & $0.69^{\circ}$ & 0,81 & $0.50^{* * *}$ & 0,95 \\
\hline & adultos - 35 a 59 anos & $0.79^{*}$ & $0.64^{* *}$ & $0.53^{* * * *}$ & $0.43^{* * * *}$ & 0,83 \\
\hline & idoso - maior 60 & 0,69 & $0.46^{\circ}$ & 0,69 & $0.24^{* * * *}$ & 1,02 \\
\hline & ref: jovens -16 a 24 anos & & & & & \\
\hline & Cor - branco & 1,09 & 1,11 & 0,93 & 0,91 & 1,21 \\
\hline & Sexo-homem & $0.80^{* *}$ & $0.65^{* * * *}$ & $0.73^{* * * *}$ & 0,79 & 1,01 \\
\hline & Estado de origem - São Paulo & 1,11 & 1,28 & 1,12 & 1,26 & $1.60^{* *}$ \\
\hline & PEA & 1,08 & 1,32 & $1.60^{.0 *}$ & 0,89 & 1,13 \\
\hline \multirow{2}{*}{ Fatores protetivos } & Situação da residência própria & 0,86 & 1,09 & 0,98 & 0,83 & 0,96 \\
\hline & Tempo de moradia & 1,00 & 0,99 & 1,00 & 0,99 & 0,99 \\
\hline \multirow{14}{*}{ Atividades rotineiras } & Meio de transporte no dia a dia & & & & & \\
\hline & carro/moto particular & $1.40^{* *}$ & 0,73 & 1,24 & 1,05 & 1,34 \\
\hline & público & 0,90 & 1,33 & $1.36^{* *}$ & 1,30 & 1,28 \\
\hline & ref: não utiliza & & & & & \\
\hline & Frequência a bares & & & & & \\
\hline & raramente & 0,89 & 1,04 & 1,01 & 0,82 & 0,81 \\
\hline & frequentemente & 0,97 & $1.59^{* *}$ & 1,12 & 1,24 & 0,80 \\
\hline & ref: nunca & & & & & \\
\hline & Índice - freq. lazer externos & $1.042^{*}$ & $1.10^{*}$ & $1.12^{* * *}$ & $1.05^{*}$ & 1,01 \\
\hline & Posse de arma & $1.82^{\circ * * *}$ & 1,50 & 0,85 & $2.56^{\circ 00}$ & 0,86 \\
\hline & Uso de bebida alcoólica & & & & & \\
\hline & socialmente & $1.28^{* *}$ & 1,32 & 1,00 & $1.57^{40 * t}$ & 0,98 \\
\hline & frequentemente & 0,97 & 1,04 & 1,35 & $2.62^{* * * *}$ & 0,67 \\
\hline & ref: nunca & & & & & \\
\hline \multirow{3}{*}{$\begin{array}{l}\text { Envolvimento } \\
\text { comunitário }\end{array}$} & Índice - participação comunitária & 1,09 & 1,12 & 1,01 & $1.27^{* * *}$ & 1,02 \\
\hline & Interação com o vizinho & $1.66^{\circ * *}$ & 1,24 & 1,11 & $1.41^{\text {te* }}$ & 1,25 \\
\hline & Índice - atividade comunitária & $1.07^{*}$ & 1,08 & 1,02 & 1,06 & 1,02 \\
\hline Confiança interp. & Índice - confiança interpessoal & $1.33^{\circ * * *}$ & 1,18 & $1.25^{\circ *}$ & 1,17 & 1,23 \\
\hline Política de seg. púb. & Taxa de homicídio (por cem mil) & 1,00 & $0.99^{*}$ & 1,00 & 1,00 & 1,01 \\
\hline \multirow{3}{*}{$\begin{array}{l}\text { Política pública - } \\
\text { distrito }\end{array}$} & Taxa de mortalidade infantil (por mil) & 1,01 & 0,99 & 0,99 & 0,99 & 1,02 \\
\hline & $\%$ nascidos vivos com baixo peso & 0,93 & 0,96 & 1,04 & 0,99 & 1,06 \\
\hline & Densidade demográfica $(\mathrm{Km} 2)$ & 1,00 & 1,00 & 1,00 & 1,00 & 1,00 \\
\hline \multirow{3}{*}{$\begin{array}{l}\text { Política pública - } \\
\text { região homogênea }\end{array}$} & $\%$ famílias com até $1 / 2$ sal. mínimo & 0,99 & 1,02 & 1,02 & 0,99 & 0,99 \\
\hline & $\%$ jovens de 15 a 17 aa não freq.escola & 1,03 & 0,94 & $0.89^{* 6 *}$ & 0,97 & 0,93 \\
\hline & $\%$ de populaçao ocupada cart. ass. & 0,99 & 1,01 & 1,02 & 1,04 & $1.08^{* *}$ \\
\hline \multicolumn{7}{|c|}{$\begin{array}{ll} & \text { Estatisticas } \\
\end{array}$} \\
\hline & 6979 & 6978 & 6978 & 6979 & 2410 \\
\hline \multicolumn{2}{|c|}{ LR chi2(41) } & 139,81 & 117,46 & 151,88 & 188,18 & 38,05 \\
\hline \multicolumn{2}{|c|}{ Prob $>$ chi 2} & 0 & 0 & 0 & 0 & 0,2133 \\
\hline \multirow{2}{*}{\multicolumn{2}{|c|}{$\begin{array}{l}\text { Pseudo R2 } \\
\text { Log likelihood }\end{array}$}} & 0,0429 & 0,0655 & 0,0524 & 0,087 & 0,0297 \\
\hline & & -1561 & -838 & -1374 & -987 & -621 \\
\hline
\end{tabular}

Fonte: Elaboração própria - Pesquisas de vitimização 2003/2008 do Insper. 
No caso de furto a pessoa, a probabilidade de vitimização é positivamente afetada pelo fato de o respondente pertencer à população economicamente ativa, ser mulher, frequentar atividades de lazer externas, utilizar transporte público e confiar mais nas pessoas. $O$ fato de ser adulto (em comparação com jovens) e de residir em uma região homogênea, com maior proporção de jovens matriculados na escola, reduz as chances de vitimização.

$\mathrm{Na}$ estimação da probabilidade de vitimização em roubo de veículo, as duas únicas variáveis significativas foram: estado de origem (ser de São Paulo) e residir em região homogênea com maior proporção da população com carteira assinada. Acreditamos que esse resultado se deva ao fato de que o local da ocorrência do evento criminal pode ser diverso do local de residência do indivíduo (único que consta na base de dados).

No caso de vitimização por agressão física, a probabilidade é explicada pela idade (jovens possuem maiores chances de vitimização se se compara às demais faixas etárias), frequência a atividades de lazer externas, pelo número de residentes no domicílio, e é inversamente afetada pelo número de banheiros na residência. Além disso, para esse tipo de vitimização, a variável "onda" (fator tempo) foi significativa.

Em suma, os resultados das estimações indicam que os fatores que impactam as chances de vitimização, bem como sua variação nos anos em questão, respondem às distintas argumentações teóricas identificadas nas seções anteriores. Um primeiro achado se refere ao fato de que um dado conjunto de variáveis - aquelas referentes ao estilo de vida ou que geram oportunidades de vitimização (que aproximam potenciais vítimas e ofensores) - se mostrou comumente significativo para todas as dinâmicas de vitimização estudadas: frequência a atividades de lazer externas, frequência a bares, utilização de transporte público, consumo de bebida alcoólica e posse de arma.

Já a significância de variáveis classificadas como atributos individuais - idade, sexo e estado de origem -, além das variáveis tipo de residência, número de residentes no domicílio e dois ou mais banheiros no domicílio, mudou com o tipo de crime. Esse resultado pode indicar que - conforme esperado - estamos diante de dinâmicas criminais distintas: de acordo com o caso em questão, uma variável aumenta a variação da vitimização entre os anos; em outros, diminui. Esse é o caso da variável idade que, em alguns casos, é fator protetivo; em outros, facilitador (fator de risco) da vitimização.

Além disso, a prevalência de algumas variáveis, como número de residentes no domicílio ou porcentagem de jovens fora da escola, afetando positivamente a vitimização, parece indicar que ela é afetada pelas condições socioeconômicas ou vulnerabilidade social do indivíduo e do local onde reside, principalmente.

Essa é também uma possível explicação para o resultado apresentado pelo conjunto das variáveis relativas a envolvimento comunitário que, sendo significativas, apresentaram sinal contrário, como esperado. Conforme indicado na seção 3, os estudos de vitimização anglo-saxões, que tradicionalmente levam em conta esses fatores, esperam que a participação e organização comunitária, ao promoverem coesão e controle social (eficácia coletiva), limitem a ocorrência desses eventos no espaço da comunidade. Contudo, tal característica - mais alta mobilização comunitária - é, no Brasil, compatível com o padrão e estilo de vida das classes mais 
populares. Diversamente do que ocorre nos países anglo-saxões, a literatura brasileira reporta maior intensidade de mobilização comunitária e interação intravizinhança nas classes mais baixas (LEEDs, 1978; ZALUAR, 1985). Ao contrário de outros países, são as classes média e alta as que apresentam um modo de vida mais isolado e menos participativo (CALDEIRA, 2008).

Outro importante argumento, que ajuda a explicar esse resultado, é trazido por Hope (2001), que diz que participação comunitária só funciona efetivamente como fator de proteção da comunidade quando há uma infraestrutura mínima. No caso brasileiro, os altos níveis de coesão social e envolvimento comunitário encontrados nas localidades mais vulneráveis, mesmo potencializados pela melhora socioeconômica vivida no período em questão, não foram capazes de enfrentar sozinhos (sem uma política de segurança pública bem focalizada) o avanço da criminalidade.

Com relação às variáveis do nível macrossocial, mostraram-se significativas a porcentagem de jovens de 15 a 17 anos matriculados na escola e a porcentagem da população com carteira assinada no interior da região homogênea, com sinal esperado. Nenhuma variável do nível do distrito administrativo afetou significativamente a vitimização, com exceção da taxa de homicídio.

A taxa de homicídio foi significativa apenas para roubo a pessoa, com sinal contrário ao esperado: quanto menor a taxa de homicídio, maior a chance de vitimização. Por outro lado, não foi significativa para outras dinâmicas de vitimização. Isso levanta a questão da utilização da taxa de homicídio como o principal indicador da política de segurança praticada em todo o Brasil, não somente no município e no
Estado de São Paulo. Além disso, contraria posições como as que guiaram as ações da polícia de Providence, nos EUA, que optou por concentrar esforços no enfrentamento dos homicídios e crimes graves, como estratégia de aumentar a capacidade de influência positiva na dinâmica criminal daquela cidade e otimizar os recursos policiais (Esserman, 2010). Mas essa parece ser a mais amplamente seguida por São Paulo, durante toda a década.

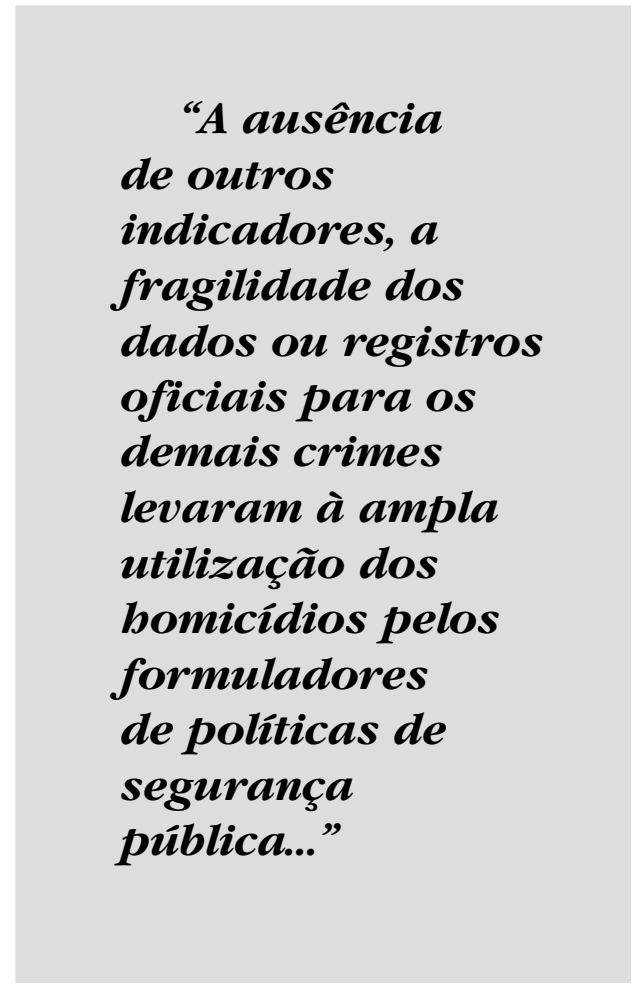

A ausência de outros indicadores, a fragilidade dos dados ou registros oficiais para os demais crimes, entre outros fatores, levaram à ampla utilização dos homicídios pelos formuladores de políticas de segurança pública, em especial as polícias, como indicador de nível de criminalidade. Dessa forma, constituiu-se em uma das principais ferramentas para o planejamento, 
monitoramento e avaliação das ações de segurança pública. O achado deste estudo, entretanto, indica que o homicídio pode não ser um bom preditor de outras dinâmicas criminais. Ações de prevenção de outros crimes ou outras formas de vitimização devem utilizar-se, diversamente, de indicadores específicos.

\section{Implicações para a política de segurança pública}

Os resultados constatam que os dados disponíveis em São Paulo problematizam a ideia de um padrão de criminalidade único para todos os crimes. Em consequência, indicam que as políticas públicas da área irão demandar decisões de gestão que definam outras prioridades e estratégias de enfrentamento para além do homicídio e, quando muito, dos chamados crimes violentos. Como segurança pública é um conceito que contempla diferentes medidas, a dinâmica regional e territorial aumenta o desafio de planejamento de ações policiais e programas em segurança pública, na medida em que torna ainda mais complexo o diagnóstico em ambientes que são dinâmicos.

Em outras palavras, a dinâmica dos fenômenos associados à política pública de segurança dificulta a fixação de parâmetros para o planejamento de alocação dos recursos disponíveis. A análise dos dados permite inferir a existência de múltiplas dimensões determinantes da vitimização e que, por conseguinte, as políticas devem aliar medidas de caráter criminal (repressivo) com medidas de políticas sociais, na perspectiva sistêmica de se pensar o macro e o micro simultaneamente.

Dessa forma, é importante que as ações policiais contemplem a integração com outras secretarias no seu planejamento. A definição dos efetivos territoriais e da logística de mobilização de forças especiais deve considerar, de forma simultânea, os diferentes territórios intraurbanos, suas tipologias, dinâmicas socioeconômicas e demográficas, bem como seu interrelacionamento.

Isso, em outras palavras, significa considerar diferentes focos e grupos de vitimização no desenho das ações e dos padrões de policiamento e prevenção. Se os homicídios mobilizaram os esforços das polícias paulistas na década de 2000, os dados aqui apresentados indicam que esses não são suficientes para garantir ambiente seguro para a população.

Paradoxalmente, para avançarmos nessa discussão, faz-se premente a adoção, por parte dos gestores públicos, de uma agenda de aperfeiçoamento e construção de indicadores de monitoramento e avaliação, bem como de investimento na qualidade dos dados existentes e na possibilidade de serem desagregados no nível do registro de cada caso, e comparados em diferentes domínios territoriais. A qualidade, a disponibilidade e a publicidade da informação não podem ser apenas um discurso político e um horizonte de longo prazo, elas têm de ser um pressuposto das políticas públicas.

(Artigo recebido em maio de 2012. Versão final em maio de 2012). 


\section{Notas}

1 As classes sociais foram construídas segundo metodologia da CCEB 2003 e 2008 (disponível no sitio www.abep.org.br).

2 Essas perspectivas foram incorporadas posteriormente por Clarke e Felson (1998) em uma perspectiva que ficou conhecida como Teoria das Oportunidades, e que fundamenta estratégias situacionais de prevenção do crime e da vitimização por crimes.

3 Os autores utilizam as seguintes variáveis: densidade populacional e residencial, para indicar variações no padrão de urbanização; porcentagem de residências chefiadas por um único adulto, para medir grau de desestruturação familiar; densidade de lojas, para verificar estruturas de oportunidade para crimes predatórios; rotatividade populacional para observar mudanças na comunidade.

4 A privação relativa foi medida pela renda média, porcentagem de famílias abaixo da linha da pobreza, Índice de Gini, porcentagem da população que é negra e a porcentagem de crianças que não vivem com ambos os pais; como indicador de dissolução familiar foi utilizada a taxa de famílias monoparentais, e a variável urbanização foi utilizada a partir do indicador densidade populacional.

5 Como indicadores da eficácia coletiva das comunidades os autores utilizam: nível de conhecimento entre as pessoas da comunidade, nível de confiança interpessoal, quantidade de amigos residentes na vizinhança e participação em atividades comunitárias.

6 Os autores analisaram o British Crime Survey e encontraram que comunidades caracterizadas por esparsas redes de amizade, jovens não supervisionados por grupos e baixa participação organizacional ajudam a aumentar taxas de crimes. Ao contrário, a densidade de redes de amizade local (residentes com mais da metade de amigos morando na comunidade) teve efeito negativo nas taxas de roubo; a participação teve também efeitos negativos em roubo e violência de estranhos.

Adotou-se a estimação do modelo logit, em vez de estimar modelos em painel, porque a base da vitimização se constitui em um pseudopainel, ou seja, apenas uma parte (não representativa) dos indivíduos foi acompanhada ao longo do tempo.

8 Estimamos o mesmo modelo, considerando apenas os 544 indivíduos em painel. Optamos por não analisar os resultados, pois esse painel não é representativo de São Paulo.

\section{Referência bibliográfica}

Adorno, S. Exclusão socioeconômica e violência urbana. Sociologias, Porto Alegre, ano 4, n. 8, jul./dez. 2002, p. 84-135.

Beato, C. C.; Peixoto, B; Andrade, M. V. Crime, oportunidade, vitimização. Revista Brasileira de Ciências Sociais, São Paulo, v. 19, n. 55, p. 73-89, 2004.

BECKER, H. Outsiders. Etudes de sociologie de la déviance. Paris, Métailié, trad. fr. 1985, 248p.

Bursik, R. Social disorganization and theories of crime. Criminology, 26:519-51, 1988.

Bursik, R.; Grasmick, H. Neighborhoods and crime: the dimensions of effective, 1993.

Caldeira, T. Cidade de Muros. São Paulo: Editora 34, 2008. 
Clarke, R. V.; Felson, M. Opportunity makes the thief: practical theory for crime prevention. Police Research Series, Paper 98. London: Home Office, 1998.

Cohen, L.; Felson, M. Social change and crime rate trends: a routine activities approach. American Sociological Review, v. 44, n. 4, p. 588-608, 1979.

Cohen, L.E., Kluegel, J. R. e Land, K.C. Social inequality and predatory criminal victimization: An Exposition and Test of a Formal Theory. American Sociological Review, v. 46, p. 505-524, 1981.

Crawford, A. Crime prevention and community Safety. 2. ed. New York: Longman, 2004.

Esserman, D. Quando o foco é o crime contra a vida: a história de uma parceria de sucesso em Providence. Entrevista. Revista Brasileira de Segurança Pública, Ano 4, 6. ed., fev./mar. 2010. Fundação João Pinheiro. Indicadores sociais de criminalidade. Belo Horizonte: Fundação João Pinheiro, 1987.

Goffman, E. Manicômios, prisões e conventos. 5. ed. São Paulo: Perspectiva, 1996.

HindeLANG et al. Victims of personal crime: an empirical foundation for a theory of personal victimization. Cambridge, MA: Ballinger Publishing Company, 1978.

Hope, T. Community crime prevention in Britain: a strategic overview. Criminology and Criminal Justice. November 2001, vol. 1, no. 4, pp. 421-439.

Insper (2009). Relatório da pesquisa de vitimização em São Paulo. Disponível em: http:// www.insper.edu.br/sites/default/files/Relatorio_Vitimizacao.pdf. Acessado em: 07/05/2010.

Kasarda, J. D. e Janowitz, M. Community attachment in mass society. American Sociological Review, p. 328-339, 1974.

Leeds, A. and Leeds, E. A Sociologia do Brasil urbano. Rio de Janeiro: Zahar Editores, 1978. LAND, K. C.; McCald, P. L.; CoHEN, L. Structural covariates of homicide rates: are there any invariances accross time and social space? American Sociological Review, 95: 922-963, 1990.

Lima, R. S. Entre palavras e números: violência, democracia e segurança pública no Brasil. São Paulo: Editora Alameda, 2011.

Lima, R. S.; Tomesani, A. M. Armed violence, urban spaces and development in Brazil. Report Small Arms Survey. Geneva. 2010.

Rabe-Hesketh, S. E Skrondal, A. Multilevel and longitudinal modeling using stata. 2nd Edition. College Station, TX: Stata Press. 2008.

SAmpson, R. J. e WiLson. W. J. Toward a theory of race, crime and urban inequality. In: Hagan e Peterson (eds). Crime and Inequality. Stanford; Stanford University Press, 1995.

Sampson, R. J. e Groves, W. B. Community structure and crime: testing social disorganization theory. American Journal of Sociology, 94: 774-802, 1989.

Sampson, R. J.; Raudenbush, S. W.; EARLS, F. Neighborhoods and violent crime: a multilevel study of collective efficacy. Science Magazine, Vol. 277, 15, august, 1997.

Skogan, W. G. Disorder and decline: crime and the spiral of decay in american neighborhoods. New York: Free Press, 1990.

Wilson, W. J. The truly disadvantaged. Chicago: The University of Chicago Press, 1987.

Zaluar, A. A máquina e a revolta. Rio de Janeiro: Brasiliense, 1985.

Exclusão e Políticas Públicas: dilemas teóricos e alternativas políticas.

Revista Brasileira de Ciências Sociais, v. 12, n. 35, out. 1997. 


\section{Anexo}

\section{Anexo I: Tabelas descritivas}

Tabela IA: Descritiva das variáveis no nível individual

\begin{tabular}{|c|c|c|c|c|c|c|}
\hline \multirow{2}{*}{ Grupos } & \multirow{2}{*}{ Variáveis } & \multicolumn{2}{|c|}{2003} & \multicolumn{2}{|c|}{2008} & \multirow{2}{*}{$\begin{array}{l}\text { Diferença } \\
\text { média }\end{array}$} \\
\hline & & média & sd & média & sd & \\
\hline \multirow{20}{*}{$\begin{array}{l}\text { Atributos } \\
\text { individuais }\end{array}$} & Local de residência-casa & 0,77 & 0,42 & 0,80 & 0,40 & $0.03^{* * *}$ \\
\hline & Número de residentes no domicílio & 4,12 & 1,77 & 3,91 & 1,75 & $-0.21^{\circ 00}$ \\
\hline & Dois ou mais banheiros & 0,35 & 0,48 & 0,38 & 0,48 & $0.02^{* *}$ \\
\hline & Escolaridade & & & & & \\
\hline & primário comp. $\backslash$ fund. incompleto & 0,30 & 0,46 & 0,27 & 0,44 & $-0.03^{* * * *}$ \\
\hline & fund. comp /médio incompleto & 0,13 & 0,34 & 0,13 & 0,34 & 0,00 \\
\hline & médio comp./sup. incompleto & 0,26 & 0,44 & 0,34 & 0,47 & $0.07^{*+\omega *}$ \\
\hline & ensino superior ou mais & 0,13 & 0,34 & 0,14 & 0,34 & 0,00 \\
\hline & Classe Social & & & & & \\
\hline & classe $C$ & 0,39 & 0,49 & 0,49 & 0,50 & $0.11^{* * * *}$ \\
\hline & classe $B$ & 0,31 & 0,46 & 0,37 & 0,48 & $0.06^{* * * *}$ \\
\hline & classe A & 0,08 & 0,27 & 0,05 & 0,22 & $-0.03^{* * *}$ \\
\hline & Idade & & & & & \\
\hline & jovens adultos - 25 a 34 anos & 0,23 & 0,42 & 0,24 & 0,43 & 0,01 \\
\hline & adultos - 35 a 59 anos & 0,38 & 0,49 & 0,39 & 0,49 & 0,01 \\
\hline & Idoso - maior 60 & 0,11 & 0,31 & 0,14 & 0,35 & $0.03^{\text {t+* }}$ \\
\hline & Cor - branco & 0,58 & 0,49 & 0,56 & 0,50 & $-0,02$ \\
\hline & Sexo - homem & 0,53 & 0,50 & 0,49 & 0,50 & $-0.04^{* * * *}$ \\
\hline & Estado de origem - São Paulo & 0,64 & 0,48 & 0,68 & 0,47 & 0,05 \\
\hline & PEA & 0,71 & 0,46 & 0,54 & 0,50 & $-0.16^{* * * *}$ \\
\hline \multirow{2}{*}{$\begin{array}{l}\text { Fatores } \\
\text { protetivos }\end{array}$} & Situação da residência própria & 0,67 & 0,47 & 0,70 & 0,46 & $0.02^{* *}$ \\
\hline & Tempo de moradia & 13,86 & 12,98 & 15,34 & 13,33 & $1.48^{* * *}$ \\
\hline \multirow{10}{*}{$\begin{array}{l}\text { Atividades } \\
\text { rotineiras }\end{array}$} & $\begin{array}{l}\text { Meios de transporte no dia a dia } \\
\text { carro/moto particular }\end{array}$ & 0,26 & 0,44 & 0,16 & 0,37 & $-0.10^{* * *}$ \\
\hline & publico & 0,52 & 0,50 & 0,43 & 0,49 & $-0.09^{* 0 * t}$ \\
\hline & Frequência a bares & & & & & \\
\hline & raramente & 0,25 & 0,43 & 0,24 & 0,43 & -0.01 \\
\hline & frequentemente & 0,31 & 0,46 & 0,13 & 0,34 & $-0.18^{.60}$ \\
\hline & Índice-frequência lazer externo & 3,96 & 2,91 & 4,00 & 2,81 & 0.04 \\
\hline & Posse de arma & 0,03 & 0,16 & 0,02 & 0,15 & 0,00 \\
\hline & Uso de bebida alcoólica & & & & & \\
\hline & socialmente & 0,18 & 0,38 & 0,21 & 0,41 & $0.04^{* * * *}$ \\
\hline & frequentemente & 0,05 & 0,23 & 0,05 & 0,23 & 0,00 \\
\hline \multirow{3}{*}{$\begin{array}{l}\text { Envolvimento } \\
\text { comunitário }\end{array}$} & Índice - participação comunitária & 1,48 & 0,81 & 1,41 & 0,77 & $-0.07^{* 0 *}$ \\
\hline & Interação com o vizinho & 0,30 & 0,46 & 0,27 & 0,44 & $-0.03^{* * *}$ \\
\hline & Índice - atividades comunitárias & 1,21 & 1,45 & 1,11 & 1,40 & $-0.10^{* * * *}$ \\
\hline $\begin{array}{l}\text { Confiança } \\
\text { interpessoal }\end{array}$ & Índice - confiança interpessoal & 0,80 & 0,49 & 0,77 & 0,50 & $-0.03^{* * *}$ \\
\hline
\end{tabular}


Tabela IB: Descritiva das variáveis no nível distrito administrativo

\begin{tabular}{l|c|c|c|c|cc}
\hline \multicolumn{1}{c|}{ Variáveis } & \multicolumn{2}{c|}{2003} & \multicolumn{2}{c|}{2008} & \multicolumn{2}{c}{ Primeira diferença } \\
& média & sd & média & sd & média & sd \\
\hline Taxa de homicídio (por cem mil) & 39,77 & 21,55 & 14,82 & 7,17 & $-24,96$ & 17,84 \\
Taxa de mortalidade infantil (por mil) & 13,17 & 3,90 & 11,54 & 4,05 & $-1,63$ & 4,62 \\
\% nascidos vivos com baixo peso & 9,43 & 1,20 & 9,29 & 0,96 & $-0,14$ & 1,58 \\
Densidade demográfica (Km2) & 10361 & 4859 & 9714 & 5447 & -646 & 2993 \\
\hline
\end{tabular}

Fonte: Elaboração própria - Pesquisas de vitimização 2003/2008 do Insper.

Tabela IC: Descritiva das variáveis no nível região homogênea

\begin{tabular}{l|c|c|c|c|cc}
\hline \multicolumn{1}{c|}{ Variáveis } & \multicolumn{2}{c|}{2003} & \multicolumn{2}{c|}{2008} & \multicolumn{2}{c}{ Primeira diferença } \\
& média & sd & média & sd & média & sd \\
\hline \% famílias com até 1/2 sal. mínimo & 18,51 & 7,48 & 20,42 & 6,21 & 1,91 & 2,27 \\
\% jovens de 15 a 17aa não freq. escola & 12,03 & 2,15 & 11,67 & 2,22 & $-0,36$ & 2,90 \\
\% de populaçao ocupada cart. ass. & 38,77 & 2,87 & 48,42 & 2,64 & 9,65 & 1,09 \\
\hline
\end{tabular}

Fonte: Elaboração própria - Pesquisas de vitimização 2003/2008 do Insper. 


\section{Resumo - Resumen - Abstract}

\section{Uma análise sistêmica: vitimização e políticas de segurança em São Paulo Betânia Peixoto; Letícia Godinho de Souza e Renato Sérgio de Lima}

Este artigo objetiva entender a vitimização em São Paulo, ao longo do tempo. Utilizamos como referencial teórico os modelos sistêmicos da dinâmica criminal. Foram utilizadas duas pesquisas realizadas pelo Insper nos anos de 2003 e 2008. Investigamos as mudanças e os fatores correlacionados, de acordo com o tipo de crime: roubo a pessoa, furto a pessoa, roubo e furto a residência, roubo e furto de veículo e agressão física. Foram considerados fatores referentes a três níveis: atributos dos respondentes, do distrito administrativo e da região homogênea onde residem. A suposição do modelo é que as características individuais e os insumos sociais, locais e macrolocais de onde o indivíduo circula seriam determinantes valiosos da probabilidade de vitimização. Os resultados mostraram que variáveis dos três níveis influenciaram a vitimização e confirmaram as hipóteses iniciais.

Palavras-chaves: Vitimização, São Paulo, modelo sistêmico

Un análisis sistémico: victimización y políticas de seguridad en São Paulo (Brasil) Betânia Peixoto; Letícia Godinho de Souza y Renato Sérgio de Lima

El presente trabajo tiene como objetivo comprender la victimización en São Paulo a lo largo del tiempo, utilizándose el modelo sistémico de la dinámica criminal como referencia teórica. Se han utilizado dos encuestas realizadas por Insper en los años 2003 y 2008. Se investigan las razones de los cambios y sus factores según el tipo de delito: el robo a la persona, hurto, robo y hurto de residencia, el robo y hurto de vehículo y asalto físico. Se consideraron factores que se refieren a tres niveles: al de los atributos de los encuestados, del distrito administrativo y de las regiones homogéneas en las que se vive. La suposición de este modelo es que las características individuales y las aportaciones sociales, locales y macrolocales de donde los individuos viven son valiosos factores determinantes de la probabilidad de victimización. Los resultados mostraron que los tres niveles de variables influyeron en la victimización y confirmaron las hipótesis iniciales.

Palabras clave: Victimización, Brasil, modelo sistémico

\section{A systemic analysis: victimization and security policies in Sao Paulo}

\section{Betânia Peixoto; Letícia Godinho de Souza and Renato Sérgio de Lima}

This paper has as main goal to understand criminal victimization in the city of São Paulo, Brazil. It has based on a systemic dynamics model perspective. We study the reasons of the victimizations rates changes between 2003 and 2008. The analysis considers five different kind of crime - individual robbery, theft, home invasion robbery, car theft and physical aggression. The covariates that had been considered are individual attributes, theirs neighborhoods and macro neighborhoods characteristics. The model assumes that individual, social, local and macrolocal attributes would be important to determinate the victimization probability. The results showed that all kinds of covariates were important to explain the change in patterns of victimization and confirmed the initial hypothesis.

Keyword: Victimization, Brazil, systemic model 


\section{Betânia Peixoto}

Doutora em Economia pela Universidade Federal de Minas Gerais. Pesquisadora independente. Contato: betania.peixoto.lemos@gmail.com

\section{Letícia Godinho de Souza}

Doutora em Ciências Políticas pela Universidade Federal de Minas Gerais. Pesquisadora e docente da Fundação João Pinheiro. Contato: leticiagodinho@gmail.com

\section{Renato Sérgio de Lima}

Doutor em Sociologia pela Universidade de São Paulo e pós-doutor pela Universidade Estadual de Campinas. Secretario executivo do Fórum Brasileiro de Segurança Publica. Contato: r.rsdlima@gmail.com 